\title{
Health Worker Opinion/Perception of Health Services provided to Patients in the Selebi Phikwe Ni-Cu Mine Area, Botswana*
}

\author{
Georges Ekosse $^{1^{*}}$, Linda de Jager ${ }^{2}$ and Dawid J. van den Heever ${ }^{3}$ \\ 1. X-Ray Diffraction Unit, Faculty of Science, University of Botswana, P/Bag 0022 Gaborone, \\ Botswana; 2. Faculty of Health and Environmental Sciences, Central University of Technology \\ Free State, P/Bag X20539 Bloemfontein, South Africa; 3. VDH Industrial Hygiene CC.PO. Box \\ 26792 Langenhoven Park, 9330, Bloemfontein, South Africa
}

*Author for Correspondence: Tel: 00267355 2569; E-mail: ekossege@mopipi.ub.bw

\begin{abstract}
SUMMARY
This study determines the prevalence of types of sicknesses and diseases affecting patients visiting health service facilities and the available health services within the Selebi Phikwe Ni-Cu mine area, Botswana. Through the administration of questionnaires and structured questions, attempts were made to establish and verify the existing human health problems at the study area by focusing on respiratory tract related symptoms of sicknesses and diseases. With the aid of statistical package for social sciences (SPSS), interpreted results from respondents indicated that all the health service providers served patients suffering from headaches, persistent coughing, chest pains, lower abdominal pains, pain when passing out urine, genital discharge and diarrhea. Seventy one percent of the health service providers indicated that their patients suffered from body weakness, $86 \%$ indicated that they had patients who suffered from recent loss of body weight, and another $86 \%$ pointed out that their patients had influenza/common cold. Other health complaints reported included unusual spitting, shortness of breath, palpitations, nausea/vomiting, diarrhoea, and constipation. Moreover the health service providers indicated that they had patients who suffered from significant illnesses of which some passed away. However if there are lacking facilities, patients are referred to bigger health service providers in the country. The findings of the study do not in general depict demarcating differences of health status of residents of the study area to those of the control site. A need therefore for further investigations to be conducted to establish relations of mining activities to human health at Selebi Phikwe is called for.
\end{abstract}

[Afr J Health Sci. 2006; 13:101-109]

${ }^{*}$ Published online before print

\section{Introduction}

Botswana enjoys the status of being one of the fastest growing economies in the world, with the exploitation of its mineral resources, which include diamonds, gold and nickel-copper (Ni$\mathrm{Cu}$ ). Selebi Phikwe township, which developed from $\mathrm{Ni}-\mathrm{Cu}$ mining activities is located in the north-eastern part of Botswana between longitudes $27^{\circ} 47^{\prime} \mathrm{E}$ and $27^{\circ} 53^{\prime} \mathrm{E}$, and latitudes $22^{\circ} 55^{\prime} \mathrm{S}$ and $22^{\circ} 00^{\prime} \mathrm{S}$. The area under investigation is approximately $250 \mathrm{~km}^{2}$ with a population of about 50,000 inhabitants and a $2.4 \%$ constant growth rate since 1991 [1]. Moreover, there has been rapid population expansion due to mining activities from < 5,000 in 1971 to the present population size characterised by $52.5 \%$ male and $47.5 \%$ female. This geometric population growth has 


\section{RESEARCH ARTICLE}

led to pressure on existing social and economic infrastructures [2], including the health status of its inhabitants.

It is thus suspected that environmental and human health problems may have ensued within Selebi Phikwe due to mining activities. Inhabitants of the area generally complain that they often suffered from illnesses of the respiratory tract and related health complications $[3,4]$. In order to further explore the predominant types of illnesses and diseases affecting residents the most, the health status of patients who visited health service facilities in the study area was investigated. This work thus presents the results of a survey that was undertaken to assess the health status of patients who visited health service facilities and the status of health services as reported by the health service providers within the Selebi Phikwe Ni-Cu mine area. The study aimed to describe the prevalence of illnesses and diseases affecting patients who visited health service facilities, which were more likely to have been caused, by the mining and smelting of $\mathrm{Ni}-\mathrm{Cu}$ in the area. This investigation furthermore afforded researchers an opportunity to explore the health services that are provided in the area.

The study area was divided into ten sites (Figure 1) in previous studies by Ekosse [3], and Ekosse et. al. [4,5,6,7]. Seven of the eight health service providers in the study area were included in the survey. The health service facilities were located in sites two, four, five, six, nine and ten (the control site located 56 $\mathrm{km}$ from Selebi Phikwe). Except for site nine which had two health service facilities, the other five sites including the control site had one each. The control site was included to compare results to the other sites located in the Selebi Phikwe area.

\section{Materials and Methods}

Through the administration of questionnaires, data was obtained from health service facilities owned by the Selebi Phikwe Town Council and the Botswana Government on patients who visited the facilities in Selebi Phikwe. The questionnaire covered demographic data of health services provided, general complaints of patients about personal health, and aspects related to death, as well as questions regarding the status of available health services. The health service providers or designated officials of the health facilities responded to the questionnaires and structured questions. The field data obtained through the administration of questionnaires were analysed using the Statistical Package for Social Sciences (SPSS) software. Cross tabulations were undertaken to see the relationships of study sites to health status of the individuals based on interpreted results.

\section{Results}

\section{Demographic data}

There were seven health service providers in the Selebi Phikwe area and the control site (one each in sites two, four, five and six, two in site nine, and one in site ten) that participated in this study. $14.2 \%$ of the health service providers reported in this study is located in site ten (control site) (Table 1). The eighth health service provider could not take part in the study due to logistical reasons. It should however be pointed that in this hospital, mainly workers of the mine and their families are treated. $85.8 \%$ of the health service providers that participated in this study are owned by the Selebi Phikwe Town Council (SPTC) and $14.2 \%$ by the Government. The physical locations of the health service providers in the Selebi Phikwe area were in accordance with development plans for the township by the Department of Town and Regional Planning [2]. In the Selebi Phikwe area, the health service providers had medical doctors, nurses, midwives and para-medical professional staff, and the purpose for patients'stay in the area included work, schooling, visit and being the hometown, according to responses obtained from the questionnaires and structured interviews (Table 1). The oldest health service facility is located in the control site (site ten), and has been there for $>50$ years, while the newest is located in site four and is $<20$ years old. The health service facilities located in sites two and five are $20-30$ years old, and the respondents were not sure of the ages of those located in sites six and nine. In a nutshell, $14 \%$ of the health service providers are $<20$ years old, 


\section{RESEARCH ARTICLE}

another $14 \%>50$ years old, $2 \%$ are $20-30$

years old and the age of $43 \%$ of the health service facilities was not known by the respondents

Figure 1: Map of Selebi Phikwe showing the different study sites

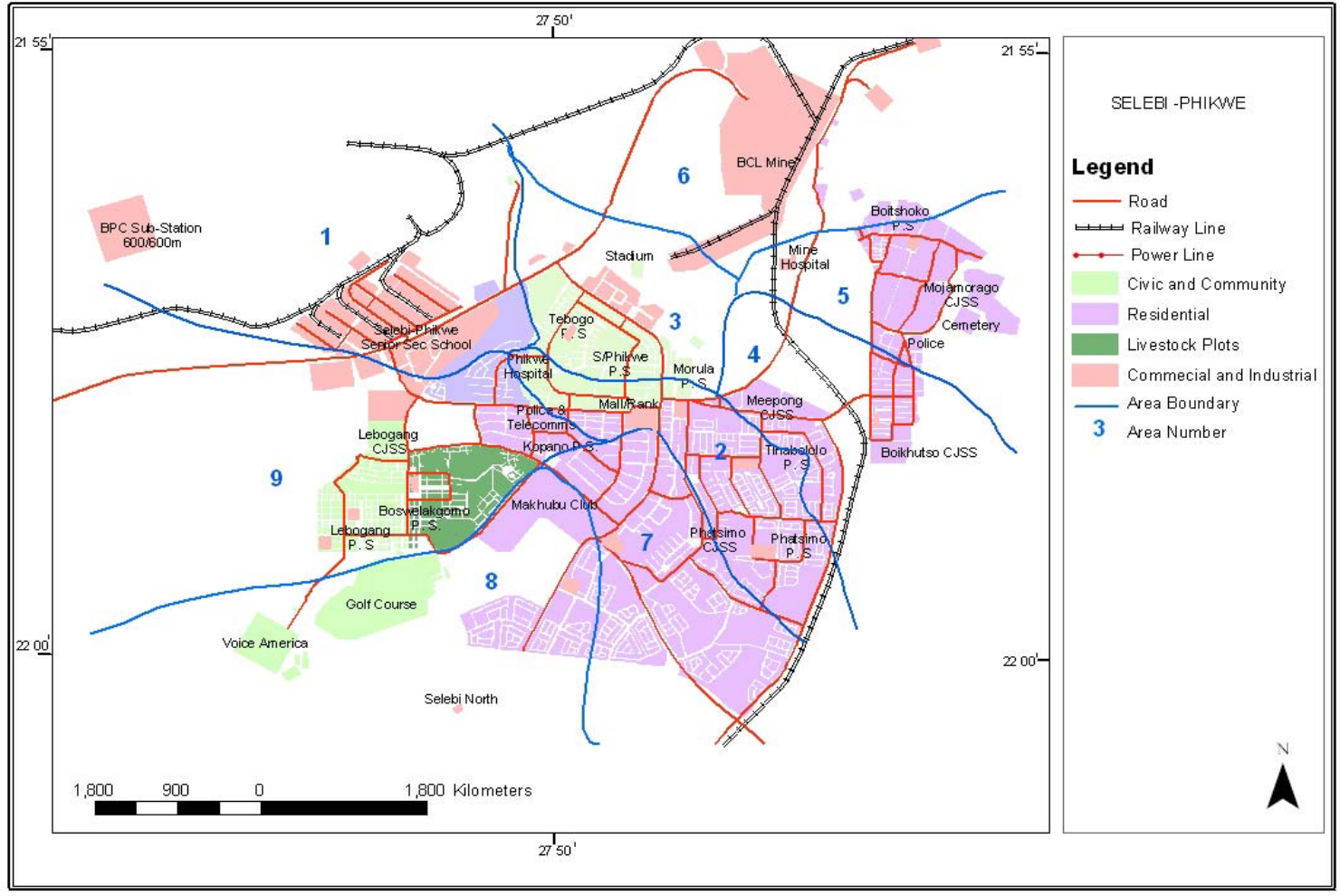

\section{Health complaints of patients}

Based on the responses obtained from the questionnaires and structured interviews (which are summarised in Table 2), health complaints of patients included general body weakness, recent and sudden loss of body weight, influenza/common cold, persistent headaches, persistent and frequent coughing, chest pains, pain in the lower abdomen, nausea and vomiting, diarrhoea, palpitations, constipation and shortness of breath. The ranges of the different percentages of occurrences of these health complaints at the different sites are also reported (Table 2). All the health service providers reported having patients who experienced genital discharge, and $33 \%$ reported that a varied number of patients complained of need to spit unusually often.

Health service providers also reported the following clinical conditions for their patients: allergies, tuberculosis, sexually transmitted diseases (STDs), hypertension, emotional or nervous problems, and asthma. The details of percentage distribution of these clinical conditions of patients are given in Table 3 . It was further reported that $17 \%$ of the health service providers had patients suffering from malaria and a $17 \%$ of the health service providers had patients who complained of bleeding tendencies.

\section{Deaths}

In sites two, five and ten, health service providers reported that deaths of patients did occur in their facilities. However, prior to deaths, a wide range of ailments, illnesses and diseases were advanced as the causes for medical visits by patients, and these were: body weakness, loss of body weight, influenza/common cold, headaches, coughing, unusual spitting, chest pain, shortness of breath, palpitations, lower abdomen pain, pain when urinating, genital discharge, nausea/vomiting, diarrhoea, and constipation. 


\section{RESEARCH ARTICLE}

Table 1: Demographic data of health service providers and patients in the study area

\begin{tabular}{|c|c|c|c|c|c|c|c|c|c|}
\hline \multicolumn{5}{|c|}{ Medical doctors per site } & \multicolumn{5}{|c|}{ Nurses per site } \\
\hline Site & None & Two & Three & $\begin{array}{l}\text { More } \\
\text { than four }\end{array}$ & Site & Three & Four & more than four & Varies \\
\hline Two & & & & 100 & Two & & & & 100 \\
\hline Four & & & 100 & & Four & & & 100 & \\
\hline Five & & 100 & & & Five & & & 100 & \\
\hline Six & 100 & & & & Six & 100 & & & \\
\hline Nine & 100 & & & & Nine & & 100 & & \\
\hline Ten & 100 & & & & Ten & 100 & & & \\
\hline Over all \% & 57 & 14 & 14 & 14 & Over all \% & 29 & 29 & 29 & 14 \\
\hline \multicolumn{5}{|c|}{ Midwives per site } & \multicolumn{5}{|c|}{ Para-medical professional staff per site } \\
\hline Site & one & two & three & Varies & Site & None & Four & Varies & $\begin{array}{l}\text { health service } \\
\text { providers } \\
\text { per site }\end{array}$ \\
\hline Two & & & & 100 & Two & & & 100 & 14.2 \\
\hline Four & & & 100 & & Four & & 100 & & 14.2 \\
\hline Five & & & 100 & & Five & 100 & & & 14.2 \\
\hline Six & 100 & & & & Six & 100 & & & 14.2 \\
\hline Nine & & 100 & & & Nine & 100 & & & 29 \\
\hline Ten & 100 & & & & Ten & 100 & & & 14.2 \\
\hline Over all \% & 29 & 29 & 29 & 14 & Over all \% & 71 & 14 & 14 & 100 \\
\hline \multicolumn{3}{|c|}{ Purpose of patients' stay } & & & \multicolumn{5}{|c|}{ Years of operation of health service provider per site } \\
\hline Site & $\begin{array}{l}\text { Wor } \\
\mathbf{k}\end{array}$ & $\begin{array}{l}\text { Home } \\
\text { town }\end{array}$ & $\begin{array}{l}\text { Work/ } \\
\text { schooling/ } \\
\text { visit/ } \\
\text { hometow } \\
\text { n }\end{array}$ & Not sure & Site & $\begin{array}{l}<20 \mathrm{yr} \\
\mathrm{s} \\
\end{array}$ & $20-30 \mathrm{yrs}$ & $>50 \mathrm{yrs}$ & Not sure \\
\hline Two & & & & 100 & Two & & 100 & & \\
\hline Four & & & 100 & & Four & 100 & & & \\
\hline Five & & & & 100 & Five & & 100 & & \\
\hline Six & 100 & & & & Six & & & & 100 \\
\hline Nine & 50 & 50 & & & Nine & & & & 100 \\
\hline Ten & & 100 & & & Ten & & & 100 & \\
\hline Over all $\%$ & 29 & 29 & 14 & 29 & Over all \% & 14 & 29 & 14 & 43 \\
\hline
\end{tabular}

Health service providers reported that patients had died because of asthma, diarrhoea, breast cancer, cancer of the colon, lung cancer, prostate cancer, malaria, AIDS-related diseases, cardiac arrest, diabetes, heart disease, meningitis, pneumonia, tuberculosis, and stroke. Unfortunately the ercentages of their patients who had died because of each of these ailments could not be approximated due to small numbers and occasional occurrences.

It was reported by $67 \%$ of the health service providers that responded that patients had lived in Selebi Phikwe prior to death and the duration of stay of their patients in the town varied widely from $<5$ years to $>45$ years. The health service providers further indicated in their responses that the ages of their deceased patients also varied from $<5$ years to $>45$ years, although most of those who died were between 25 years and 40 years - quite a young age to die. In terms of study sites of the deceased, the health service providers responded that their patients who had died had lived in all the different sites included in this study. Also, with regard to previous employment of the deceased, all the different occupations were represented as indicated in the responses obtained from the questionnaires and structured questions. 


\section{RESEARCH ARTICLE}

However, housewives, supermarket /shop staff and mine workers were the most affected professions. It is not certain why these categories of patients were the most affected by death but one could deduce that exposure to environmental air pollution and ingestion of contaminated worms may be some of the contributory reasons. Unfortunately, the health service providers were not sure what percentages of the various occupations were affected.

Table 2: Percentage distribution of general health complaints of patients who visited health service providers in the Selebi Phikwe area

\begin{tabular}{|c|c|c|c|c|c|c|c|c|c|c|c|}
\hline \multicolumn{4}{|c|}{ General body weakness } & \multicolumn{5}{|c|}{$\begin{array}{l}\text { Sudden loss of body } \\
\text { weight }\end{array}$} & \multicolumn{3}{|c|}{ Influenza/common cold } \\
\hline Site & $<20 \%$ & $30-40 \%$ & Varies & Site & $<20 \%$ & $20-30 \%$ & $40-50 \%$ & Varies & Site & $\begin{array}{l}20- \\
30 \% \\
\end{array}$ & Varies \\
\hline Two & & 100 & & Two & & & 100 & & Two & & 100 \\
\hline Four & 100 & & & Four & 100 & & & & Four & & 100 \\
\hline Nine & & & 100 & Five & & 100 & & & Five & 100 & \\
\hline Ten & 100 & & & Six & & & & 100 & Six & & 100 \\
\hline $\begin{array}{l}\text { Over } \\
\text { all \% }\end{array}$ & 40 & 20 & 40 & Nine & & & & 100 & Nine & & 100 \\
\hline \multirow{2}{*}{\multicolumn{4}{|c|}{$\begin{array}{l}\begin{array}{l}\text { Persistent } \\
\text { coughing }\end{array} \\
\end{array}$}} & $\begin{array}{l}\text { Over } \\
\text { all \% }\end{array}$ & 17 & 17 & 17 & 50 & $\begin{array}{l}\text { Over } \\
\text { all \% }\end{array}$ & 17 & 83 \\
\hline & & & & \multicolumn{3}{|c|}{ Headaches } & \multicolumn{5}{|c|}{ Chest pains } \\
\hline Site & $<20 \%$ & $40-50 \%$ & Varies & Site & $<20 \%$ & Varies & Site & $<20 \%$ & Varies & $\begin{array}{l}50- \\
60 \% \\
\end{array}$ & \\
\hline Two & & & 100 & Two & & 100 & Two & & 100 & & \\
\hline Four & & & 100 & Four & 100 & & Four & & 100 & & \\
\hline Five & 100 & & & Five & 100 & & Five & 100 & & & \\
\hline Six & & & 100 & Six & & 100 & Six & & 100 & & \\
\hline Nine & & & 100 & Nine & & 100 & Nine & & 100 & & \\
\hline Ten & & 100 & & Ten & & 100 & Ten & & & 100 & \\
\hline $\begin{array}{l}\text { Over } \\
\text { all \% }\end{array}$ & 14 & 14 & 71 & $\begin{array}{l}\text { Over } \\
\text { all \% }\end{array}$ & 29 & 71 & $\begin{array}{l}\text { Over } \\
\text { all \% }\end{array}$ & 14 & 71 & 14 & \\
\hline \multicolumn{5}{|c|}{ Pain in the lower abdomen } & \multicolumn{3}{|c|}{ Nausea and vomiting } & \multicolumn{4}{|l|}{ Diarrhoea } \\
\hline Site & $<20 \%$ & $30-40 \%$ & $40-50 \%$ & $\begin{array}{l}\text { Varie } \\
\mathrm{s}\end{array}$ & Site & $<20 \%$ & Varies & Site & $<20 \%$ & $\begin{array}{l}40- \\
50 \% \\
\end{array}$ & Varies \\
\hline Two & & & & 100 & Two & & 100 & Two & & & 100 \\
\hline Four & 100 & & & & Four & 100 & & Four & 100 & & \\
\hline Five & 100 & & & & Five & 100 & & Five & 100 & & \\
\hline Six & & & & 100 & Six & & 100 & Six & & & 100 \\
\hline Nine & & 50 & 50 & & Nine & & 100 & Nine & & & 100 \\
\hline Ten & & & & 100 & Ten & & 100 & Ten & & 100 & \\
\hline $\begin{array}{l}\text { Over } \\
\text { all \% }\end{array}$ & 29 & 14 & 14 & 43 & $\begin{array}{l}\text { Over } \\
\text { all \% }\end{array}$ & 29 & 71 & $\begin{array}{ll}\begin{array}{l}\text { Over } \\
\%\end{array} & \text { all } \\
\end{array}$ & 29 & 14 & 57 \\
\hline \multicolumn{4}{|c|}{ Palpitations } & \multicolumn{3}{|c|}{ Constipation } & \multicolumn{3}{|c|}{ Shortness of breath } & & \\
\hline Site & $<20 \%$ & $30-40 \%$ & Varies & Site & $\begin{array}{l}< \\
20 \% \\
\end{array}$ & Varies & Site & $<20 \%$ & Varies & & \\
\hline Two & & & 100 & Two & & 100 & Two & & 100 & & \\
\hline Four & 100 & & & Four & 100 & & Four & 100 & & & \\
\hline Five & 100 & & & Five & 100 & & Five & 100 & & & \\
\hline Six & & & 100 & Six & & 100 & Six & & 100 & & \\
\hline Nine & & 50 & 50 & Nine & 50 & 50 & Nine & & 100 & & \\
\hline $\begin{array}{l}\text { Over } \\
\text { all \% }\end{array}$ & 33 & 17 & 50 & Ten & & 100 & Ten & & 100 & & \\
\hline & & & & $\begin{array}{l}\text { Over } \\
\text { all \% }\end{array}$ & 43 & 57 & $\begin{array}{l}\text { Over } \\
\text { all \% }\end{array}$ & 33 & 67 & & \\
\hline
\end{tabular}


RESEARCH ARTICLE

Table 3: Percentage distribution of reported clinical conditions of patients who visited health service providers in the Selebi Phikwe area

\begin{tabular}{|c|c|c|c|c|c|c|c|c|}
\hline \multicolumn{4}{|l|}{ Allergies } & \multicolumn{5}{|c|}{ Tuberculosis } \\
\hline Site & $<20 \%$ & $20-30 \%$ & Varies & Site & $<20 \%$ & $20-30 \%$ & $30-40 \%$ & Varies \\
\hline Two & & & 100 & Two & & & & 100 \\
\hline Four & 100 & & & Four & 100 & & & \\
\hline Five & & 100 & & Five & 100 & & & \\
\hline Six & & & 100 & Six & 0 & 100 & & \\
\hline Nine & 50 & & 50 & Nine & 50 & & 50 & \\
\hline Ten & 100 & & & Ten & 100 & & & \\
\hline Over all & 43 & 14 & 43 & Over all & 57 & 14 & 14 & 14 \\
\hline \multicolumn{5}{|c|}{ Sexually transmitted diseases } & \multicolumn{4}{|c|}{ Hypertension } \\
\hline Site & $<20 \%$ & $20-30 \%$ & $30-40 \%$ & Varies & Site & $<20 \%$ & $40-50 \%$ & Varies \\
\hline Two & & & & 100 & Two & & & 100 \\
\hline Four & 100 & & & & Four & & & 100 \\
\hline Five & & 100 & & & Five & 100 & & \\
\hline Six & & & & 100 & Six & & & 100 \\
\hline Nine & 50 & & 50 & & Nine & 50 & 50 & \\
\hline Ten & & 100 & & & Ten & & & 100 \\
\hline Over all & 29 & 29 & 14 & 29 & Over all & 29 & 14 & 57 \\
\hline \multicolumn{4}{|c|}{ Emotional or nervous problems } & \multicolumn{5}{|l|}{ Asthma } \\
\hline Site & $<20 \%$ & $20-30 \%$ & Varies & Site & $<20 \%$ & Varies & & \\
\hline Two & & & 100 & Two & & 100 & & \\
\hline Four & 100 & & & Four & & 100 & & \\
\hline Five & & 100 & & Five & 100 & & & \\
\hline Six & & & 100 & Six & & 100 & & \\
\hline Nine & 100 & & & Nine & 50 & 50 & & \\
\hline Over all & 40 & 20 & 40 & Over all & 33 & 67 & & \\
\hline
\end{tabular}

\section{Health services provided}

When health service providers were questioned on whether they had patients who suffered from major or significant illnesses, $67 \%$ of them responded positively. $33 \%$ of the health service providers reported that $<20 \%$ of their patients suffered from major or significant illnesses, while another $33 \%$ indicated that a varied number of their patients suffered from major or significant illnesses. Similarly, $33 \%$ of the health service providers indicated that their patients who had suffered from major or significant illnesses had been cured and another $33 \%$ of the health service providers indicated that their patients who suffered from major or significant illnesses had not been cured.
In cases where major or significant illnesses were concerned, $84 \%$ of the health service providers responded that they referred patients to better equipped health facilities in the country. Within the Selebi Phikwe area, $33 \%$ of the health service providers, which are primary health care units, referred their patients only to the hospital in Selebi Phikwe. Another $33 \%$ of the health service providers referred their patients either to the hospital in Selebi Phikwe or the Nyangabwe Government referral hospital, Francistown. 17\% of the health service providers referred their patients to the Nyangabwe Government referral hospital, Francistown or the distant Princess Marina Referral hospital, Gaborone. Another $17 \%$ referred patients to other health facilities in Zimbabwe and South Africa.

When questioned on whether patients were medically examined, $67 \%$ of the health service providers responded affirmatively. The main 


\section{RESEARCH ARTICLE}

tests performed included the following: x-ray, lung function, blood and urine tests. Health service providers were also asked if patients visited the health facilities because of nervous problems, tuberculosis, malaria, bilharzia, high blood pressure, allergies, asthma, bleeding tendencies and sexually transmitted diseases (STDs). Their responses were positive in all respects except for bilharzia.

\section{Discussion}

Staffing of health service provider institutions has remained a problem in Botswana because of the lack of specialised training institutions, a small population and very low population density $[2,8,9]$. One mining area with a similar set-up to that of Selebi Phikwe is West Papua in Indonesia, which remains a major transmigration receiving area. As in the Selebi Phikwe area in Botswana [8,9], in West Papua, the overall health status is the lowest in Indonesia and the problems of access to and availability of services imply that a high proportion of the population remains underserved [10]. In West Papua in Indonesia, with its population of around 400000 , there is only one hospital with 70 beds, and 15 health centres with a doctor in the 13 sub-districts covering an area of 53,000 square kilometres [10]. In Selebi Phikwe, however, the situation is a good deal better with a population of about 50000 that have immediate access to two hospitals and six primary health facilities.

Patients were admitted into health facilities because of some of general health complaints excluding complaints of frequent coughing, regular headaches, pains when urinating, unusual desire to spit, and unusual genital discharge. They were also admitted into health facilities because of AIDS-related issues, asthma and persistent chest pains. However, unexpected general body weakness which is not associated with physical effort such as dieting or exercises, sudden and significant loss of body weight, and frequent nausea and vomiting have been attributed to AIDS and AIDS-related diseases, as well as tuberculosis and cancer [11,12,13]. These three diseases (AIDS and AIDS-related diseases, tuberculosis and cancer) as well as malaria, hypertension and STDs may not be associated with the mining activities at Selebi Phikwe. It is therefore not clear which of these illnesses and diseases affecting patients in the area are a direct result of the mining activities. However, ailments such as chest pains, coughing, constipation, diarrhoea, influenza/common colds, headaches, recent loss of body weight, lower abdominal pain, and palpitations could be the result of environmental air pollution or ingestion of contaminated phane worms. Environmental air pollution or ingestion of contaminated phane worms, could ultimately result in allergies, asthma, bleeding tendencies and hypertension.

Health complaints of patients indicating persistent chest pains, frequent experiences of shortness of breath, asthmatic attacks, persistent coughing and several occurrences of influenza/common colds could be symptoms associated with respiratory tract diseases that could ultimately lead to COPD or even lung cancer $[14,15,16]$. Frequent and persistent headaches, influenza/common colds and acute chest pains have been diagnosed as precursors of asthma, lung cancer, hypertension and chronic bronchitis. At Selebi Phikwe patients had complained of these symptoms and deaths had been reported of patients as a result. While there may be several causes of these diseases, at Selebi Phikwe PAM and gaseous fumes could be contributory.

As mentioned earlier, West Papua in Indonesia has mining areas which are similar in setting to Selebi Phikwe. Comparing West Papua, Indonesia to Selebi Phikwe in terms of diseases, influenza/common cold and tuberculosis seem to occur in both areas. In West Papua, however, gonorrhoea is widespread [10]. Chlamydia is the major cause of sterilisation among local women there and this disease has been allowed to spread untreated despite its simple treatment using antibiotics. As a result, the birth rate has dropped by $80 \%$ in some areas [10]. In this study, sterilisation among the women in Selebi Phikwe was not investigated. Other diseases being treated in West Papua by missionaries in remote areas include ear disease, influenza, filariasis and ascariasis. Infectious diseases such as tuberculosis and hepatitis are also widespread. Leprosy, despite its eradication around the world, is as high as 88 per 10,000 people in some regions in West Papua [10]. There were no cases of leprosy identified in the Selebi Phikwe area. 


\section{RESEARCH ARTICLE}

It should be noted that the health services at Selebi Phikwe provide moderately for primary health care. Patients are however referred to the referral hospitals which are the Princess Marina Hospital, Gaborone; Nyangabgwe Hospital, Francistown; and the Psychiatric Hospital, Lobatse for more serious illnesses. Prevalent diseases in the area are handled at the referral hospitals because of more resources.

\section{Conclusion}

This study aimed at investigating the health services provided and the health status of patients as reported by health service providers within the Selebi Phikwe Ni-Cu mine area. From previous studies $[3,4,5,6,17]$, sulphur dioxide, which is emitted from the roasting of the ore, particulate air matter, tailings dump, contaminated soils, contaminated Colophospermum mopane and Imbrasia belina were identified as sources of pollution which could possibly have contributed to the negative health effects of patients as depicted by their health service providers within Selebi Phikwe.

In this study, we have reported in a broad sense on an investigation which was conducted among health service providers through the administration of questionnaires and structured interviews. Only one hospital did not participate in the study. However, the patients attending this hospital share similar commonalities such as proximity to the mines and locality of habitation and neighbourhood with other residents of Selebi Phikwe. In this regard, non-participation of this one hospital in this study may have had only a small degree of influence on the findings.

Data was generated in areas related to demographical aspects, general complaints about personal health, medical history, and aspects related to death. With the aid of SPSS software, attempts were made to quantify the research findings. Common ailments, illnesses and diseases reported to be affecting patients as indicated by the health service providers in the area included asthma, bleeding tendencies, heart disease, high blood pressure, allergies, general body weakness, chest pain, coughing, constipation, diarrhoea, influenza/common cold, headache, loss of body weight, lower abdominal pain, nausea and vomiting, palpitations, shortness of breath, unusual spitting, genital discharge, and cancer. Deaths were also reported.

Considering the results obtained in this study, there were no clear demarcating differences in the health status of patients living in the control site (site ten) from that of patients in the other nine study sites. This could not be demonstrated most probably because of the tool chosen. However, patients living in sites two, four, five, six and nine appeared to be more affected, probably because the health service providers were located in those sites, making medical visits much easier for the patients. Patients from sites four, five and six which are located close to mining activities recorded the highest levels of medical visits for the different ailments, sicknesses and diseases.

\section{References}

1. Botswana Government National Census National population and housing census report. Gaborone, Botswana. 1991. p159

2. Department of Town and Regional Planning., Selebi Phikwe Development Plan: 1996 - 2016. Selebi Phikwe Town Council, Botswana. 1996; p 55.

3. Ekosse G. Heavy metals concentrations in the biophysical environment around the $\mathrm{Ni}-\mathrm{Cu}$ mine and smelter/concentrator plant, Botswana. Submitted to the Global Journal of Environmental Science. 2004

4. Ekosse G; Chaoka R; Alemaw BF; van den Heever DJ and de Jager L. Distribution of heavy metals concentrations around the Selebi Phikwe $\mathrm{Ni}-\mathrm{Cu}$ mine area, south eastern Botswana. In Ngowi AB; Feldman C; Matshediso B; Mathiba J and Segawa S. (Editors) Proceedings of the $1^{\text {st }}$ Botswana International Conference on Mining. Challenges facing the minerals industry in 


\section{RESEARCH ARTICLE}

developing countries. 20-22

November, 2002, pp157-166.

5. Ekosse G; van den Heever DJ; de Jager L and Totolo O. Environmental mineralogy of soils around Selebi Phikwe nickel-copper plant, Botswana. International Journal of Environmental Studies. 2003; 60: 251-262.

6. Ekosse G; van den Heever DJ; de Jager L and Totolo O. Environmental chemistry and mineralogy of particulate air matter around Selebi Phikwe nickel-copper plant, Botswana. Minerals Engineering. 2004; 17: 349-353.

7. Ekosse G; Van den Heever DJ; De Jager L and Totolo O. Mineralogy of tailings dump around Selebi Phikwe nickel-copper plant, Botswana. Journal of Applied Sciences \& Environmental Management. 2004; 8: 37-44.

8. Botswana Government. National development Plan 8., 1998-2003. Government Printer, Gaborone, Botswana. 1998. p56

9. Botswana Government. Vision 2016. Presidential task group for a long term vision for Botswana. Government Printer, Gaborone, Botswana. 2003; p 69.

10. West Papua information kit., 2003: Social change, environment, and critical threats Prepared HTML version by Alan Kaylor Cline of Austin, Texas, USA, cline@cs.utexas.edu.

http://www.cs.utexas.edu/users/cline/p apua/health.htm. Accessed 16 June 2005American Thoracic Society, Centres for Disease Control, Atlanta, USA, and the Infectious Diseases Society of America. Treatment of Tuberculosis. Recommendations and reports. American Journal of Respiratory and Critical Care Medicine. 2003; 167: 603-662.

11. National Cancer Institute. Fatigue. Patient version. Modified 12/17/2003.

Cancer.gov.

http://www.cancer.gov/templates.

Accessed 3 January 2004.
12. National Comprehensive Cancer Network. Nausea and vomiting. Treatment guidelines for patients with cancer. American Cancer Society. 01-50M-9418-HCP. 2004

13. Australian Lung Foundation. COPD Chronic bronchitis and emphysema. Australian Lung Foundation Lung Net. Web: http://www.lungnet.org.au. 2003. Accessed 14 August 2003.

14. National Heart, Lung and Blood Institute. The lungs in health and disease. National Heart, Lung and Blood Institute Division of Lung Diseases, Office of Prevention, Education, and Control. USA. 2003; pp 39.

15. Human Respiratory System. Diseases of the lungs. http://users.ren.com/jkmball.ma.ultran et/BiologyPages/P/Pulmonary.html. 2003

16. Asare B. Perceptions on socioeconomic and environmental impacts of mining in Botswana: A case study of the Selebi Phikwe $\mathrm{Cu}-\mathrm{Ni}$ mine. Unpublished MSc thesis, University of Botswana, Gaborone, Botswana. 1999; p 126. 